\title{
Effect of post weld heat treatment on the 6061 aluminum alloy produced by ultrasonic additive manufacturing ${ }^{1}$
}

\author{
M.N. Gussev ${ }^{1 *}$, N. Sridharan ${ }^{1,2}$, M. Norfolk ${ }^{3}$, K.A. Terrani ${ }^{1}$, S.S.Babu ${ }^{1,2}$ \\ ${ }^{1}$ Oak Ridge National Laboratory, Oak Ridge, TN 37831 \\ ${ }^{2}$ University of Tennessee, Knoxville, TN 37916 \\ ${ }^{3}$ Fabrisonic LLC, Columbus, OH 43221 \\ *Corresponding author. \\ Postal address: \\ 1 Bethel Valley Road, P.O. Box 2008, MS-6151 \\ Telephone number: \\ (865) 574-4456 \\ Fax number: \\ (865) 574-6095 \\ E-mail address: \\ gussevmn@ornl.gov
}

\begin{abstract}
:
Ultrasonic additive manufacturing (UAM) is a solid-state additive manufacturing technique employing principles of ultrasonic welding coupled with mechanized tape layering to fabricate fully functional parts. However, parts fabricated using UAM often exhibit a reduction in strength levels when loaded normal to the welding interfaces (Z-direction). In this work, the effect of post-weld heat treatments (PWHT) on Al-6061 builds fabricated using the UAM process was explored aiming to improve the mechanical strength of the UAM builds. Tensile testing with digital image correlation (DIC) coupled with metallography along with multi-scale structure characterization (SEM-EBSD) was used to investigate and rationalize the mechanical performance of the UAM builds. It was established that PWHTs may improve the Z-strength level by the factor of $\sim 3 \div 3.5$ (from $\sim 46 \mathrm{MPa}$ to $177 \mathrm{MPa}$ ). The improvements in the strength level were primarily aided by material aging and grain growth across the bond interface.
\end{abstract}

\section{Keywords}

Ultrasonic additive manufacturing, Post weld heat treatment, Electron Back Scatter Diffraction, Digital Image correlation, Tensile tests.

\footnotetext{
${ }^{1}$ This manuscript has been authored by UT-Battelle, LLC, under Contract No. DE-AC0500OR22725 with the U.S. Department of Energy. The United States Government retains and the publisher, by accepting the article for publication, acknowledges that the United States Government retains a non-exclusive, paid-up, irrevocable, worldwide license to publish or reproduce the published form of this manuscript, or allow others to do so, for United States Government purposes. The Department of Energy will provide public access to these results of federally sponsored research in accordance with the DOE Public Access Plan (http://energy.gov/downloads/doe-public-access-plan).
} 


\section{Introduction:}

Ultrasonic additive manufacturing (UAM) is a solid state hybrid manufacturing process that uses high-frequency (usually $20 \mathrm{kHz}$ ) ultrasonic vibrations to fabricate parts in a layered manner $[1,2]$. Compared to traditional industrial technologies, UAM allows for complex shaped parts with internal channels or cavities [1] and has the ability to fabricate fully functional hybrid materials. The unique nature of UAM sets it apart from other additive manufacturing techniques since it may be combined with fiber embedding to fabricate composite materials [3,4]. During the UAM process, temperature rise at the interface may reach several hundred degrees $[5,6]$; however, if this value is below some critical limit, UAM may be used to fabricate dissimilar metal welds without any risk of intermetallic formation [7,8]. Like other additive manufacturing techniques, the UAM builds exhibit anisotropic mechanical properties and have relatively low strength levels when loaded perpendicular to the welding layers [9] (referred to as Z-direction in the rest of the paper). For the case of UAM, the drop in the Z-axis strength may be close to 80$85 \%$ of the base material strength $[10,11]$.

The low Z-direction strength level has been attributed, as a rule, to the presence of voids [12] and the lack of bonding between the layers [13]. To increase the mechanical strengths, researchers in the past have used statistical techniques $[10,14,15]$ to find the process parameter range maximizing the mechanical strength and minimize the void fraction at the interface [12]. Since the frequency of vibration is usually fixed at $20 \mathrm{kHz}$, the process parameters normally varied are the normal force, vibration amplitude, and the sonotrode travel speed. A detailed description of these parameters is provided elsewhere [9] and are omitted here. Optimizing process parameters is a way to enhance the bond strength levels of the additive manufactured components, and recently strength improvement has been reported [16]. Nevertheless, it may be necessary to use other post processing treatments to improve the mechanical properties of the builds.

Post weld heat treatments (PWHT) have been used successfully to improve the properties of welded parts [17,18]. For common welding techniques, like tungsten inert gas welding (TIG), the PWHT post-weld heat treatments is a common way to enhance the performance of the weldment [17-19]. However, while the literature on the effect of heat treatments on the microstructure of Al-alloys exist [20,21], there are limited studies [8,16] dealing with the impact of PWHT on the performance of the UAM-builds. Since PWHT offers significant potential to improve the properties of the UAM-builds [16], it is important to explore its effect on the microstructure and mechanical properties in more detail. The present work investigates the mechanical behavior and structure of the UAM-produced aluminum alloy subjected to different post-welding thermal treatments. 


\section{Experimental work:}

The commercially available $150-\mu \mathrm{m}$ tapes of Al-6061 H-18 alloy were used in this study. The composition of the material is shown in Table 1. The UAM-builds were fabricated using the $9 \mathrm{~kW}$ UAM machine at the Fabrisonic LLC (Columbus, OH) [1]. Previously optimized parameters were used for the fabrication of the builds. A vibration amplitude of $35 \mu \mathrm{m}$, the normal force of $5000 \mathrm{~N}$, and travel speed of $85 \mathrm{~mm} / \mathrm{s}$ were used to fabricate the UAM build with dimensions $150 \times 25 \times 20 \mathrm{~mm}$ in $\mathrm{X}, \mathrm{Y}$, and Z-directions (Figure 1), respectively. The temperature was maintained at $75^{\circ} \mathrm{C}$ during the process. A monolithic bulk commercial alloy 6061 in the T-6 condition (termed below as a "reference") was used to provide a baseline for comparison of the mechanical properties.

Table 1. Alloy element compositions (wt. \%).

\begin{tabular}{|c|c|c|c|c|c|c|c|c|c|}
\hline $\mathrm{Al}$ & $\mathrm{Mg}$ & $\mathrm{Si}$ & $\mathrm{Fe}$ & $\mathrm{Cu}$ & $\mathrm{Cr}$ & $\mathrm{Ti}$ & $\mathrm{Mn}$ & $\mathrm{Zn}$ & $\mathrm{Ni}$ \\
\hline Balance & 0.86 & 0.66 & 0.35 & 0.23 & 0.13 & 0.084 & 0.082 & 0.077 & 0.015 \\
\hline
\end{tabular}

The UAM-builds were sectioned using a low-speed saw and mounted and polished using standard metallography techniques. The characterization of the as-received material has been published elsewhere [11]. Tensile dog-bone specimens, Figure 2, were manufactured using electro-discharge machining (EDM) and special care was taken to avoid any accidental loading or bending of the specimens. Specimens were extracted in three directions: $\mathrm{X}$ - along the direction of the travel of the sonotrode, $\mathrm{Y}$ - along the sonotrode vibration direction, and $\mathrm{Z}$ along the build direction, with the load applied normal to the interfaces, Figure 1. Post weld heat treatments were performed in an inert argon atmosphere by heating the specimens sealed in quartz capsules filled with argon.

The thermal cycles and process details for the heat treatment are given in Table 2. Due to the nature of the UAM process (high strain rate deformation, near adiabatic heating), the local temperature could reach beyond the solvus temperature in Al-6061 and would potentially solutionize the interface region. Since Al-6061 is a precipitation strengthened alloy, it was hypothesized that annealing at $180^{\circ} \mathrm{C}-8 \mathrm{~h}$ would help to restore the $\mathrm{Mg}_{2} \mathrm{Si}$ strengthening precipitate and improve the properties. Recrystallization was expected to be limited if any. Annealing at $330^{\circ} \mathrm{C}-1 \mathrm{~h}$ was conducted to recrystallize the grains at the interface and anneal away the onset of strain localizations at the interface. 


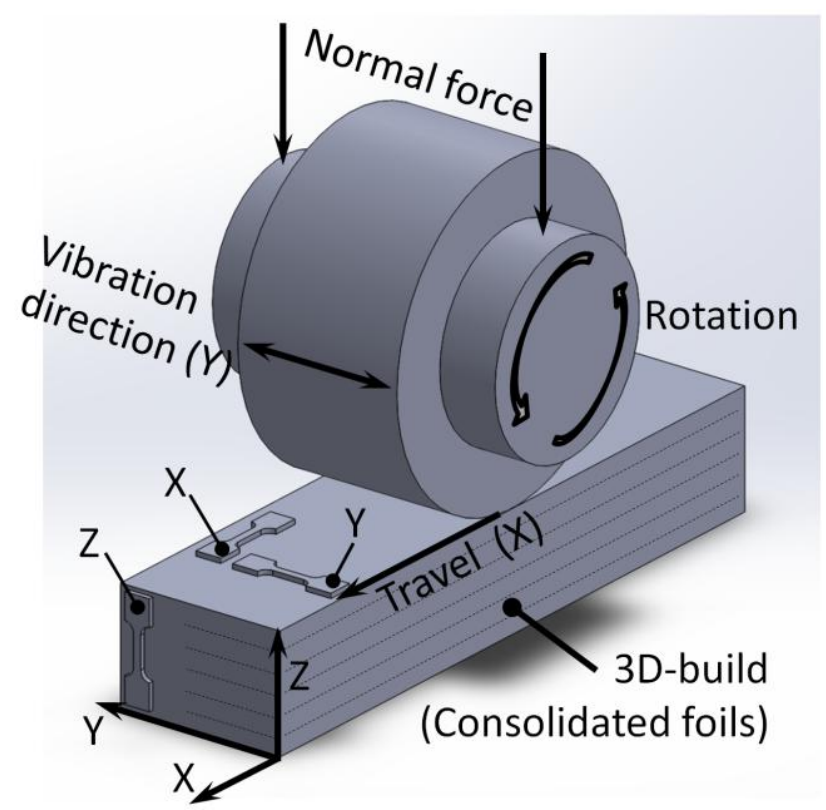

Figure 1. Schematic of the UAM process, the definition of the coordinate system, and the orientation of tensile specimens.

The final heat treatment was meant to solutionize and age the samples. The samples were solutionized at $580^{\circ} \mathrm{C}$ for $1 \mathrm{~h}$, quenched in water, and aged at $180^{\circ} \mathrm{C}$ for 8 hours. It was expected that heating at temperatures $>0.5 \mathrm{~T}_{\mathrm{m}}$ would cause extensive grain growth across the welding interfaces, consequently improving the strength along the Z-direction. The heat treatments were not optimized for the peak strength level, as performed elsewhere [22,23]; the aim of the present study was to systematically evaluate the effect of heat treatments on the mechanical properties and microstructure of UAM builds.

Table 2. Post weld heat treatment details

\begin{tabular}{|c|c|}
\hline$\#$ & Description \\
\hline 1 & Aging at $180^{\circ} \mathrm{C}$ during $8 \mathrm{~h}$. \\
\hline 2 & Annealing at $330^{\circ} \mathrm{C}, 1 \mathrm{~h}$. \\
\hline 3 & Solutionizing at $580^{\circ} \mathrm{C}$ for $1 \mathrm{~h}$ followed by aging at $180^{\circ} \mathrm{C}, 8 \mathrm{~h}$. \\
\hline
\end{tabular}

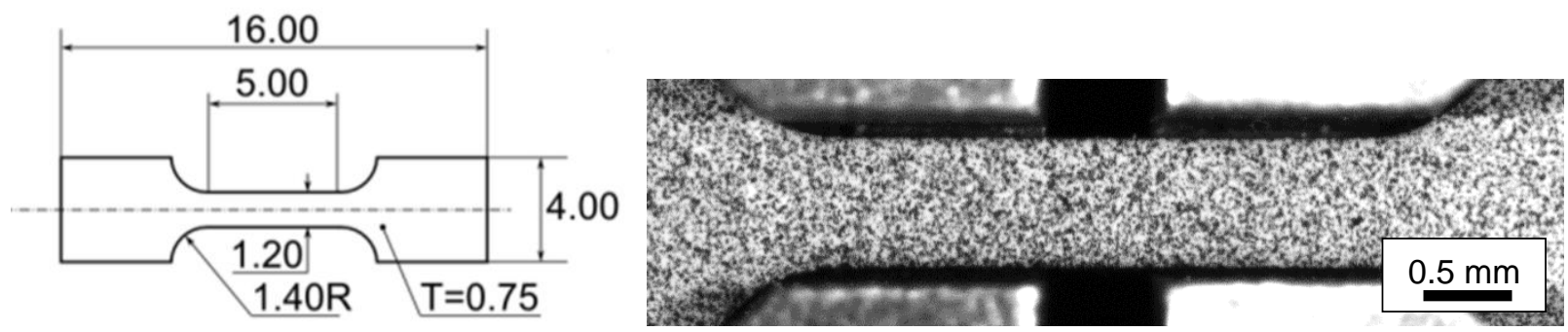

Figure 2. Geometry and dimensions (in $\mathrm{mm}$ ) of the tensile specimen. "T" designates thickness. Dimensional tolerances: gauge length $\pm 0.02 \mathrm{~mm}$, gauge width $\pm 0.02 \mathrm{~mm}$, specimen thickness 
$\pm 0.01 \mathrm{~mm}$, and other dimensions $\pm 0.04 \mathrm{~mm}$. The image at the right shows the DIC speckle pattern.

Tensile tests were performed on an MTS Insight 2-52 one-column tensile screw machine. At least five specimens were tested per each direction in the as-built condition, and three per condition after PWHT. All specimens were shoulder loaded using special grips and tested at room temperature with a strain rate of $10^{-3} \mathrm{~s}^{-1}$. Non-contact strain measurements were performed using digital image correlation (DIC) approach to analyze the deformation localization and necking. The details of the DIC method are discussed in detail elsewhere [24]. Being coupled with SEM, DIC allows for strain analysis at grain and sub-grain level [25], which may be important in the future work. In the context of the present work, DIC allows for deformation band visualization and analyzing strain localization.

Before the testing, the specimens were painted with white and black paint forming random speckle pattern, Figure 2. A single Allied Vision GX3300 digital camera was employed to capture images during the tests; depending on the lens employed, the resolution in different tests varied from $\sim 5$ to $12 \mu \mathrm{m}$ per pixel. Camera frame rate was 16 frames per second (fps), but only one image per second was stored for the analysis. It is pertinent to mention that the frame rate limits the ability to detect and analyze phenomena occurring between the frames taken. After the test, 2D strain fields and strain rate values were calculated using VIC-2D commercial software and home-made program utilizing common DIC algorithms. Single-camera DIC system allows for surface (or plain) strain analysis only; as a consequence of this limitation, the out-of-plane strain (e.g. in the neck) cannot be measured which may lead to some uncertainty [24] in analyzing the necking or deformation bands.

Following mechanical testing, fractography was performed to investigate the nature of the failure mechanism. After that, to analyze the structure, tensile specimens were mounted on cold mounting epoxy and prepared using standard metallography techniques. Following the polishing step, samples were examined using optical microscopy to check for the void fraction and in particular if the PWHT had served to decrease the void fraction at the interface. EBSD analysis was performed on a JEOL 6500 FEG scanning electron microscope to investigate the effect of heat treatment on the microstructure of the interfaces. The operational voltage varied in different tests from $10 \mathrm{kV}$ to $20 \mathrm{kV}$ depending on grain size and magnification.

\section{Results and Discussions}

\section{Strength and ductility before and after post weld heat treatments}

Figure 3 shows a typical structure of the UAM specimens prior and after PWHT. The voids formed specific chains revealing the added material layers. In most cases, the void length was 
below 80-100 $\mu \mathrm{m}$. It is clear that the post weld heat treatments did not influence void density or distribution. Void formation and geometry during the UAM process is described in detail elsewhere [11] and will not be discussed in the present work.

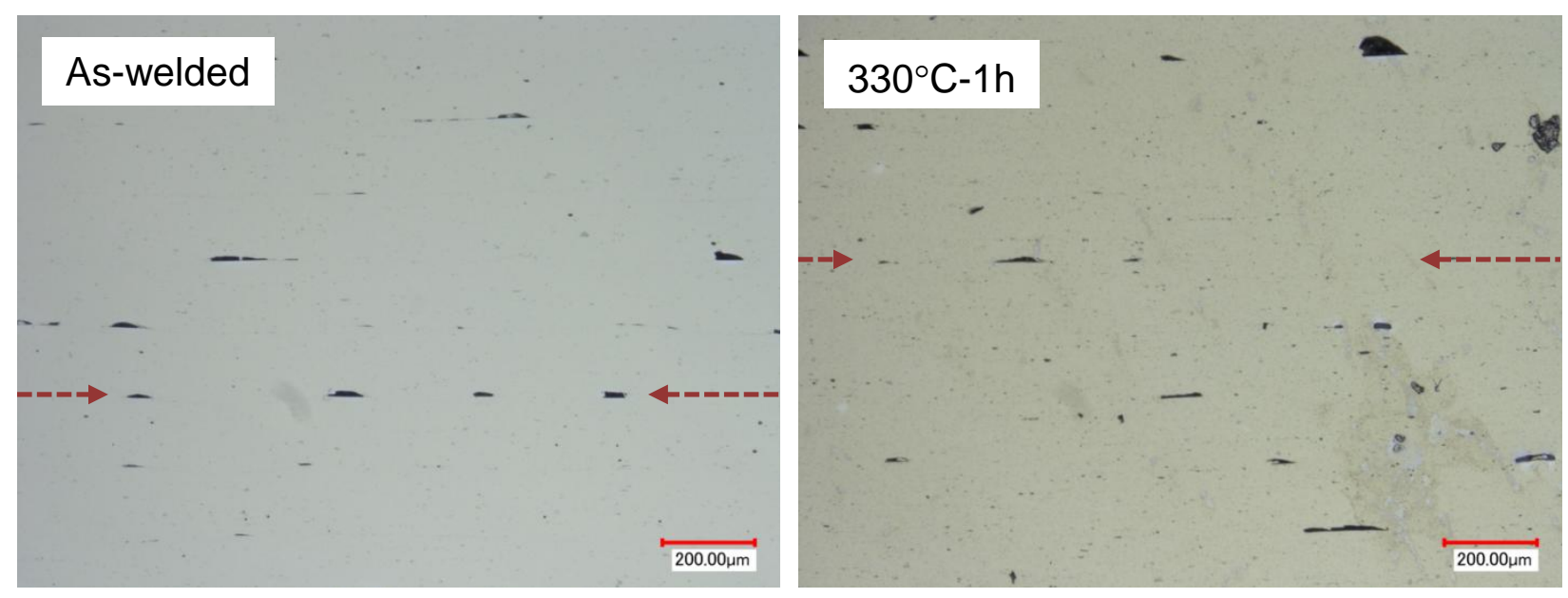

Figure 3. A representative cross-sectional view of the UAM produced material before and after annealing. One may see multiple voids grouping along the welding interfaces (few interfaces are shown by dashed arrows). Optic microscopy.

Figure 4 shows representative tensile curves and Table 3 presents the summary mechanical test results. As shown in Figure 4, for the "as-received" X and Y UAM specimens the necking initiates spontaneously after yield stress was reached; uniform ductility was low enough. The tensile curves were smooth; no force drops were observed. The UAM build material was softer and less ductile in the $\mathrm{X}$ and $\mathrm{Y}$ directions, compared to the reference alloy, Table 3 . When loaded normal to the interfaces (Z-direction), the specimens showed practically zero ductility and macroscopically brittle fracture behavior. The fracture stress did not exceed $\sim 50 \mathrm{MPa}(\sim 20-25 \%$ of the maximum load for X-and Y-specimens). Similar behavior was observed in [11].

In order to recrystallize the interfaces, the samples were heat treated at $330^{\circ} \mathrm{C}$ for $1 \mathrm{~h}$. In addition to the UAM builds, the monolithic Al-6061 alloy was also tested after this heat treatment cycle to provide a base line for comparison. The monolithic material shows a yield strength of $117 \mathrm{MPa}$ while the UAM Y-sample after heat treatment shows a yield strength of $127 \mathrm{MPa}$ and a total elongation of $23.6 \%$ which is significantly higher. However, when loaded along the $\mathrm{X}$-axis despite the apparent reduction in yield strength, the ductility is retained. It needs to be pointed out that properties, when loaded along $\mathrm{X}$ and $\mathrm{Y}$, were expected to be identical since they are both in plain directions of the original rolled tape. However, even between the $\mathrm{X}$ and $\mathrm{Y}$ directions pronounced anisotropy was observed, that could be related to the texturing effects and, probably, void geometry. 
As-received

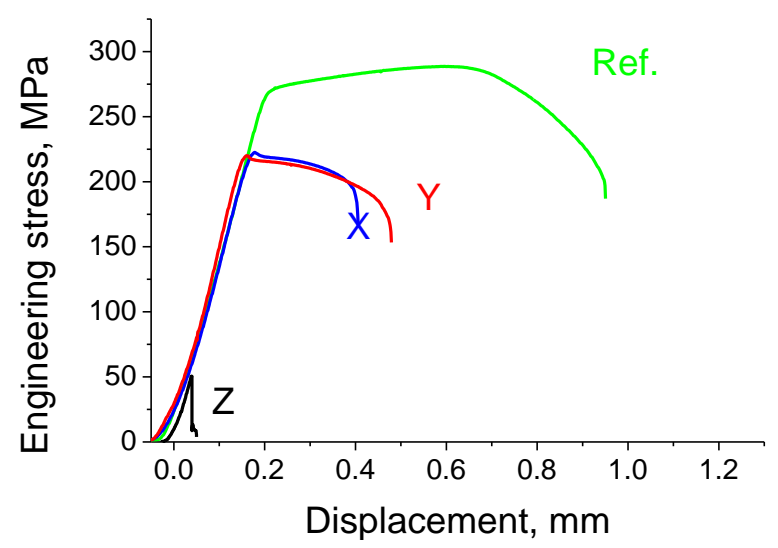

$180^{\circ} \mathrm{C}-8 \mathrm{~h}$

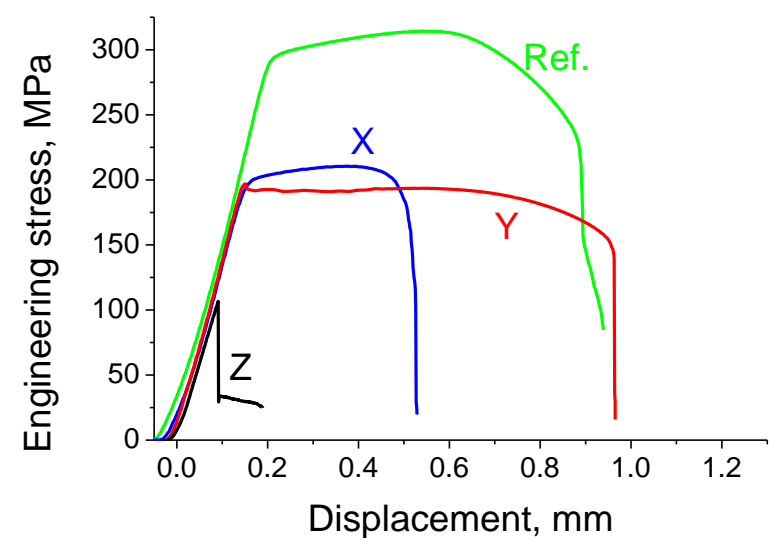

$330^{\circ} \mathrm{C}-1 \mathrm{~h}$
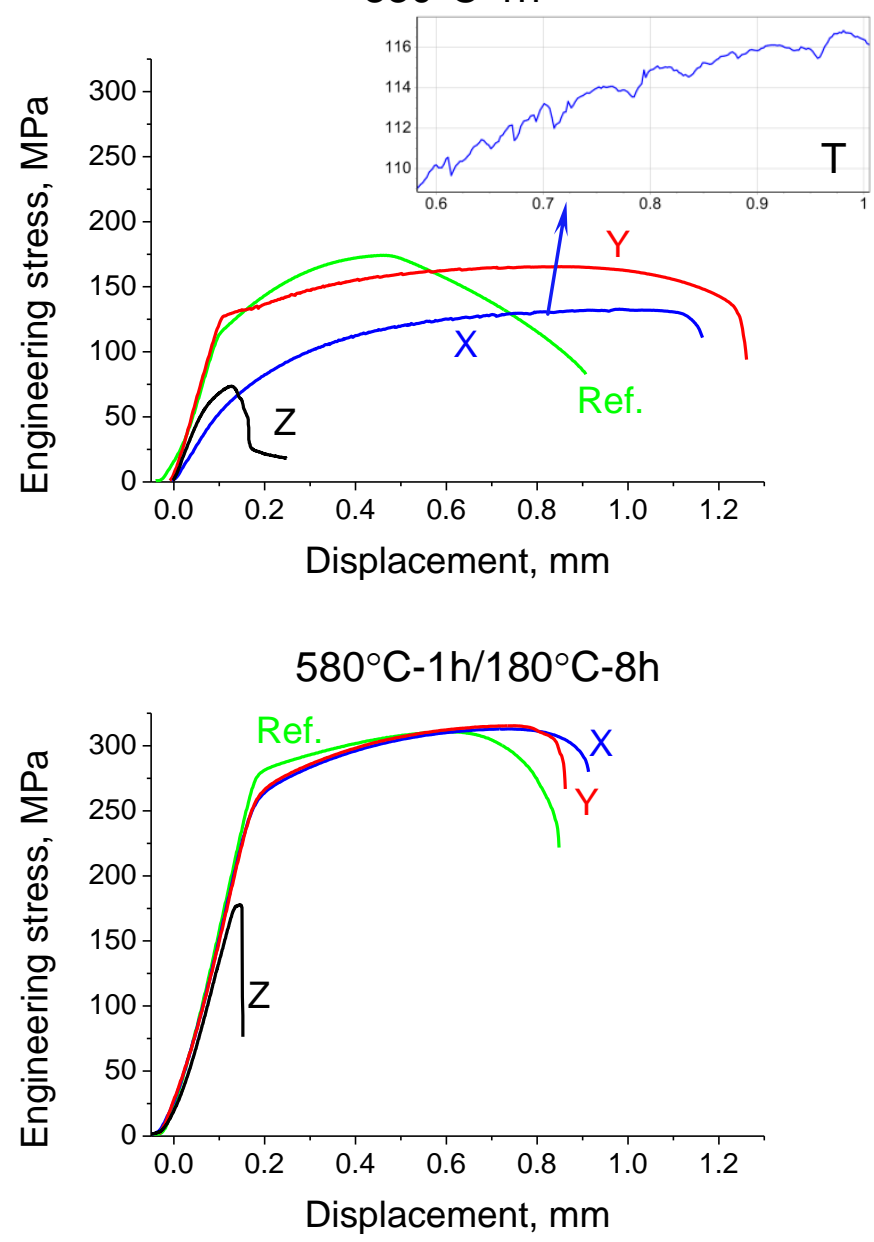

Figure 4. Engineering tensile curves illustrating the effect of annealing on the mechanical behavior of the UAM-produced 6061-alloy. Insertion (T) shows the force drops (Portevin-LeChatelier effect (PLC) observed for X and Y specimens annealed at $330^{\circ} \mathrm{C}-1 \mathrm{~h}$.

For the samples heat treated at $330^{\circ} \mathrm{C}$ for $1 \mathrm{~h}$, the tensile curves showed force drops $(\sim 2-4 \mathrm{MPa}$ in amplitude which is comparable to [26]) and serrated flow, specific signs of the PLC effect [26-28]. One of the driving forces of the PLC may be the interaction of solute atoms with dislocations [26,27], the phenomenon strongly depends on test temperature and strain rate; however, its detailed analysis is out of the present work scopes. Based on the more or less uniform variation in the stress-strain data it is concluded that the bands observed here belongs to a type A, where the bands nucleate near the specimen head and propagate along the gauge [26]. The PLC phenomenon needs to be analyzed since it has a direct bearing on the final mechanical properties of the builds. The local load drops and serrations are known to cause severe strain localization at the interface thereby reducing the overall ductility of the sample. However, the 
most important observation in this section is the improvement in the fracture strength when loaded along the $\mathrm{Z}$ direction. Analyzing the stress-strain curve, Figure 4, one can see a small increase in fracture stress and a descending "tail" in the Z-specimens, which is suggestive of some local ductile effects.

Table 3. Mechanical properties of the specimens fabricated using UAM and reference specimens before and after heat treatments.

\begin{tabular}{|c|c|c|c|c|c|c|}
\hline \multirow[b]{2}{*}{ Type } & \multirow[b]{2}{*}{ Thermo-treatment } & \multicolumn{4}{|c|}{ Mechanical properties } & \multirow[b]{2}{*}{ PLC-effect } \\
\hline & & $\begin{array}{l}\text { Yield stress, } \\
\mathrm{MPa}\end{array}$ & $\begin{array}{c}\text { Ultimate } \\
\text { stress, MPa }\end{array}$ & $\begin{array}{c}\text { Uniform } \\
\text { elongation, } \\
\%\end{array}$ & $\begin{array}{c}\text { Total } \\
\text { elongation, } \\
\%\end{array}$ & \\
\hline \multirow{4}{*}{$\begin{array}{l}\text { Reference } \\
\text { (Wrought) }\end{array}$} & - & 294 & 315 & 7.2 & 15.4 & No \\
\hline & $330^{\circ} \mathrm{C}-1 \mathrm{~h}$ & 117 & 178 & 6.1 & 18.8 & Yes \\
\hline & $180^{\circ} \mathrm{C}-8 \mathrm{~h}$ & 293 & 314 & 6.5 & 17.5 & No \\
\hline & $\begin{array}{r}580^{\circ} \mathrm{C}-1 \mathrm{~h} / 180^{\circ} \mathrm{C}- \\
8 \mathrm{~h}\end{array}$ & 277 & 311 & 8.2 & 14.0 & No \\
\hline \multirow{4}{*}{$\mathrm{X}$} & - & 217 & 225 & 1.1 & 5.1 & No \\
\hline & $330^{\circ} \mathrm{C}-1 \mathrm{~h}$ & 59.8 & 132.8 & 14.7 & 22.3 & Yes \\
\hline & $180^{\circ} \mathrm{C}-8 \mathrm{~h}$ & 197.0 & 210.6 & 4.3 & 8.9 & No \\
\hline & $\begin{array}{r}580^{\circ} \mathrm{C}-1 \mathrm{~h} / 180^{\circ} \mathrm{C}- \\
8 \mathrm{~h}\end{array}$ & 254.3 & 313.0 & 10.1 & 14.4 & No \\
\hline \multirow{4}{*}{$\mathrm{Y}$} & - & 221.1 & 223.7 & 0.5 & 6.0 & No \\
\hline & $330^{\circ} \mathrm{C}-1 \mathrm{~h}$ & 127.6 & 165.5 & 14.3 & 23.6 & Yes \\
\hline & $180^{\circ} \mathrm{C}-8 \mathrm{~h}$ & 195.1 & 196.9 & 0.1 & 17.1 & Yes \\
\hline & $\begin{array}{r}580^{\circ} \mathrm{C}-1 \mathrm{~h} / 180^{\circ} \mathrm{C}- \\
8 \mathrm{~h}\end{array}$ & 259.7 & 315.4 & 10.6 & 13.6 & No \\
\hline \multirow{4}{*}{$\mathrm{Z}^{*}$} & - & $46.2^{*}$ & - & - & - & - \\
\hline & $330^{\circ} \mathrm{C}-1 \mathrm{~h}$ & 59.0 & 73.5 & 0.9 & 4.5 & - \\
\hline & $180^{\circ} \mathrm{C}-8 \mathrm{~h}$ & $106.0^{*}$ & - & - & - & - \\
\hline & $\begin{array}{r}580^{\circ} \mathrm{C}-1 \mathrm{~h} / 180^{\circ} \mathrm{C}- \\
8 \mathrm{~h}\end{array}$ & $177.6^{*}$ & - & - & - & - \\
\hline
\end{tabular}

* Fracture stress.

Figure 4 also shows the samples in the aged condition $\left(180^{\circ} \mathrm{C}-1 \mathrm{~h}\right)$. The aging was performed to form the strengthening precipitates. Though the parent tape for UAM was provided in the H-18 condition which is cold rolled, the interface could have experienced significant local rises in temperature during welding due to the near adiabatic heating resulting in the solutionizing. For example, temperature values up to $250^{\circ} \mathrm{C}$ were directly measured via infrared camera mounted to observe the welding area [5]; peak temperatures up to $370-390^{\circ} \mathrm{C}$ were registered during UAM 
via direct thermocouple measurements [6]. This is only macroscopic temperature rise being measured; local high strain rate deformation may cause even larger temperatures due to the adiabatic heating [29]. Taking into account these results, it was hypothesized that an aging treatment could, in fact, result in precipitation of the strengthening precipitates, thereby improving the mechanical strength. Due to the low temperature in this treatment, the recrystallization and grain growth across the interface were not expected to occur. The monolithic reference alloy was not sensitive to this treatment; its mechanical properties (Figure 4, Table 3) remain unchanged. Interestingly, the X- and Y-specimens showed a modest decrease in yield stress and improvements in ductility. Although no pronounced force drops and serration flow was observed at the tensile curves, the specimens loaded along the $\mathrm{Y}$ direction, as a rule, demonstrated propagating deformation bands led to high ductility. This finding will be discussed in detail below.

Aging at $180^{\circ} \mathrm{C}-8 \mathrm{~h}$ greatly enhanced the Z-strength levels; average strength practically doubled (from $\sim 44 \mathrm{MPa}$ to $106 \mathrm{MPa}$ ). A similar result has been previously observed after accumulative roll bonding (ARB) of Al-6061 alloy [28]; the strength and ductility of ARB material enhanced after an extended aging treatment. The improvements in properties were attributed [28] to a synergic effect of precipitation, reduction in dislocation density, and mild structure coarsening.

Finally, solutionizing and an aging treatment was given to the specimens. As described above the samples were heated to $580^{\circ} \mathrm{C}$ for one hour followed by quenching and artificially aged for $180^{\circ} \mathrm{C}$ for 8 hours. Since this temperature was just slightly below nominal solidus temperature $\left(\sim 600^{\circ} \mathrm{C}\right)$ it was hypothesized to result in significant grain growth across the interfaces consequently improving the strength along the Z-direction. As follows from the results (see the tensile curves in Figure 4 and summary data in Table 3), the specimens loaded along their X- and Y-directions showed mechanical properties similar to that of reference wrought material. When loaded along the $\mathrm{Z}$ axis, the fracture stress increased more than a factor of 3, compared to the aswelded conditions.

Generalizing the results on mechanical behavior, it is clear that PWHT offers significant improvements in the mechanical properties of the UAM-builds. By employing the solutionizing and aging treatment, the properties along the $\mathrm{X}$ and $\mathrm{Y}$ directions were completely recovered. Annealing was the most beneficial for Z-strength, which reached more than three-fold value compared to the as-received material.

\section{Analysis of deformation behavior}

As shown in the previous section in Figure 4, some specimens showed clear signs of PortevinLe-Chatelier effect [26,30,31] -force drops, forming repetitious patterns. This phenomenon was analyzed in detail using DIC. The local strain rates were obtained by numerical derivation of the 
DIC-measured strain fields. Figure 5 shows the temporal variation of the local strain rate along the tensile specimen gauge. One can see that the areas of localized deformation (e.g., local strain rate $\mathrm{d} \varepsilon \gg 10^{-3} \mathrm{~s}^{-1}$ ) appeared at the gauge and tended to move along the specimen length. From Figure 5 it is clear that the morphology of the PLC bands is a strong function of the nature of the heat treated condition. PLC bands are typically classified into three types A, B, and C [26,27]. Type $\mathrm{C}$ being a $\mathrm{PLC}$ band nucleating randomly while type $\mathrm{A}$ being a continuous propagating band and type $B$ is intermittent [27].
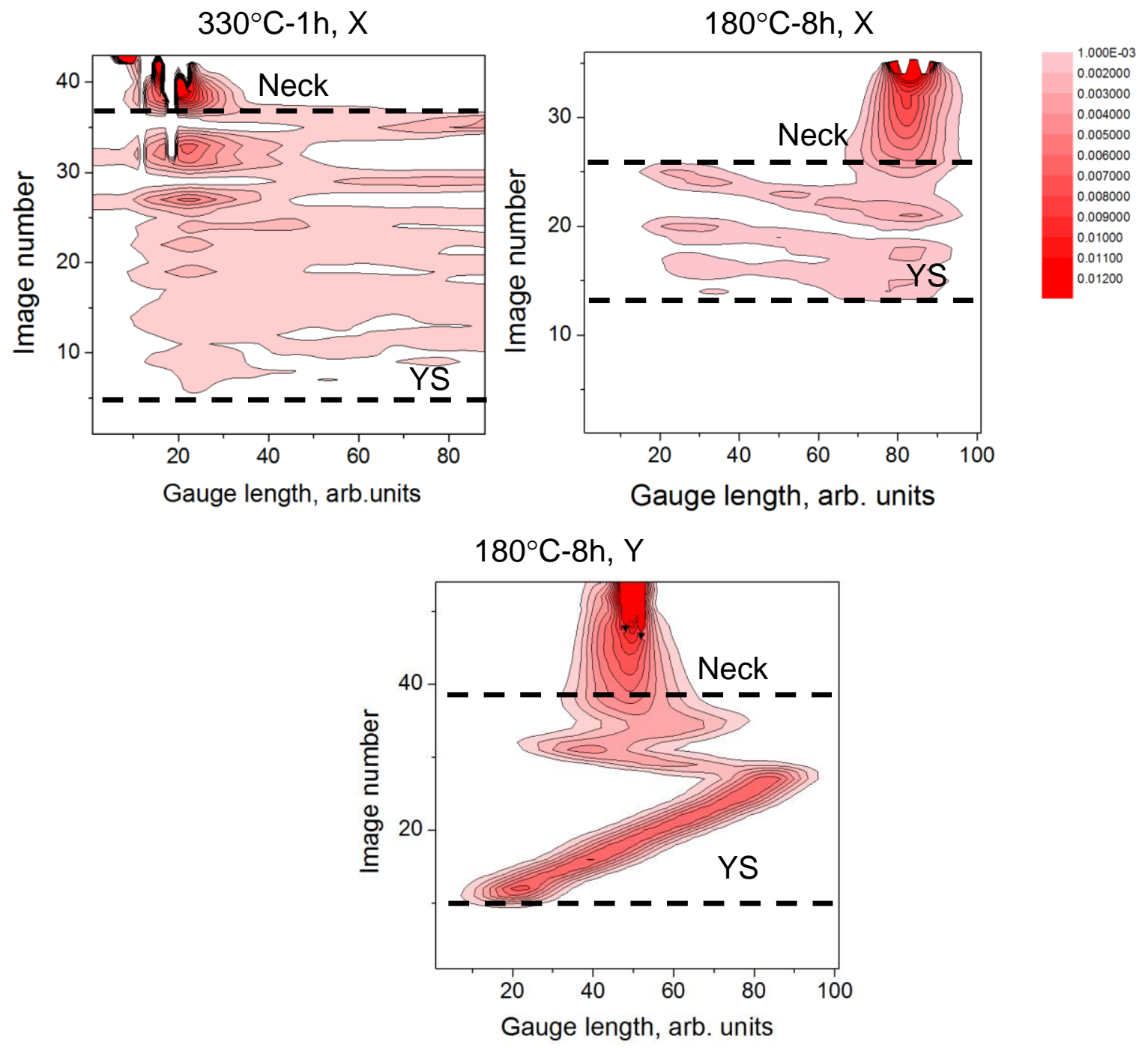

Figure 5. Strain rate evolution along the specimen gauge as a function of time (image number). To underline strain localization, nominal strain rate $\left(10^{-3} \mathrm{~s}^{-1}\right)$ and smaller values are shown as a background (white color). von Mises strain definition and Green-Lagrange strain tensor were used. "YS" and "Neck" (with the corresponding dashed lines) designates the yield stress and stable neck appearance, respectively. The color scale is the same for all images.

For the recrystallized specimens $\left(330^{\circ} \mathrm{C}-1 \mathrm{~h}\right)$, the nature of the band is, most likely, a propagating Type A band with a minimal strain localization. These bands appeared and passed the same 
location multiple times. Such behavior is characteristic of an annealed material where the defect density is reduced greatly thereby reducing the probability of a solute atom encountering and getting trapped by a dislocation. Qualitatively, the observed behavior is close to the numerical simulations of the PLC-effect, conducted by McCormick and Ling [32]; the model and numerical experiments revealed repetitive band propagation with final strain localization in the neck. The simulation [32] showed more regular band evolution pattern, compared to the direct experiment; small irregularity in the material structure make the band behavior less predictable. Similar results on the deformation localization and band formation were also obtained by Zhemchuznikova et al. [33] for bulk 6061-alloy.

Aging at $180^{\circ} \mathrm{C}-8 \mathrm{~h}$ showed a change in the tensile behavior. The force drops in the stress-strain curves become hard to distinguish from the noise. However, the DIC results (Figure 5) however clear show the signs of non-homogeneous deformation: appearance and propagation of the deformation bands.

Interestingly, the deformation localization type and strain amplitude within band strongly depend on the specimen orientation ( $\mathrm{X}$ or $\mathrm{Y}$ ) reflecting the inherent anisotropy in the UAM process. For the $\mathrm{X}$-specimen, the amplitude of strain inside the bands was small enough; the bands were not visible by naked eye and required digital processing to be revealed. In contrast, the Y-specimens, aged at $180^{\circ} \mathrm{C}-8 \mathrm{~h}$, often showed macroscopic, high-amplitude and easy-visible deformation bands, Figure 5. The bands passed along the gauge only one or two times, but local strain level increase, caused by the band passage, was 5 to 10 times larger compared to the ordinary PLC discussed above. The specimen orientation ( $\mathrm{X}$ or $\mathrm{Y}$ ) was a key factor influencing this type of behavior (no such high-amplitude bands in $\mathrm{X}$ ).

General peculiarities of the deformation band formation were studied by Maziere et al. [34] performed numerical modeling and analysis of PLC-phenomena. It was shown that band formation required a complex deformation hardening[34] law with strain softening within some strain range; The PLC effect was also strain-rate sensitive [34]. Regarding results shown in Figure 5, it is unlikely the high strain amplitude bands in the Y-specimens were caused by processes in solid solution only. One may speculate that complex, UAM-induced multi-layer structure with voids along the layers also contributed to the phenomenon. Additionally, PLC may be sensitive to the texture, as discussed by Shen et. al [35]; thus, the texture existing in the material after UAM-manufacturing [11] also might have contributed to the phenomenon. To understand it in detail, a special, focused research will be needed in the future.

\section{Fracture behavior}

Figure 6 and Figure 7 show the fracture surface for the Z-specimens at different conditions. The as fabricated builds, when loaded along the Z-axis, showed macroscopically brittle fracture with zero ductility, Table 3 . Fractography analysis revealed cleavage fracture surface with few small ductile spots, Figure 6. Previous work showed that these ductile spots were a result of the void 
coalescence [11]. In all cases, cracks nucleated and propagated along the welding interface, and the fracture occurred along a single layer.
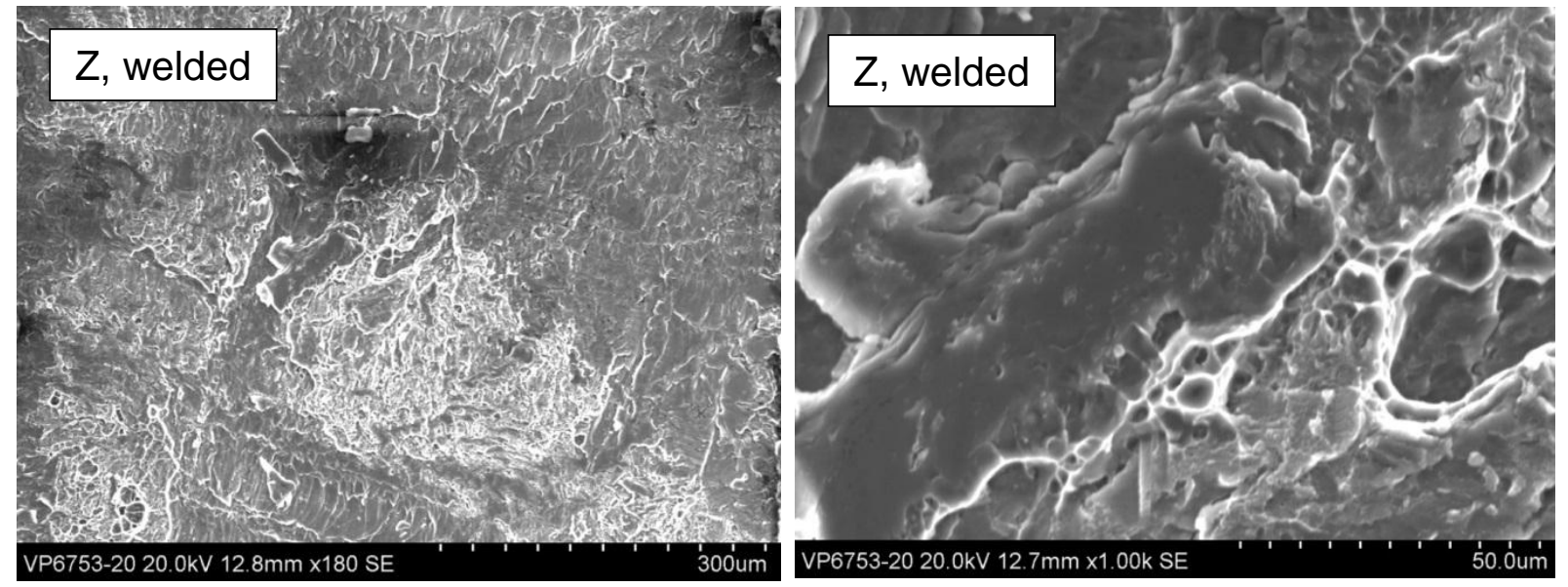

Figure 6. Fracture surface of Z-specimens before annealing.
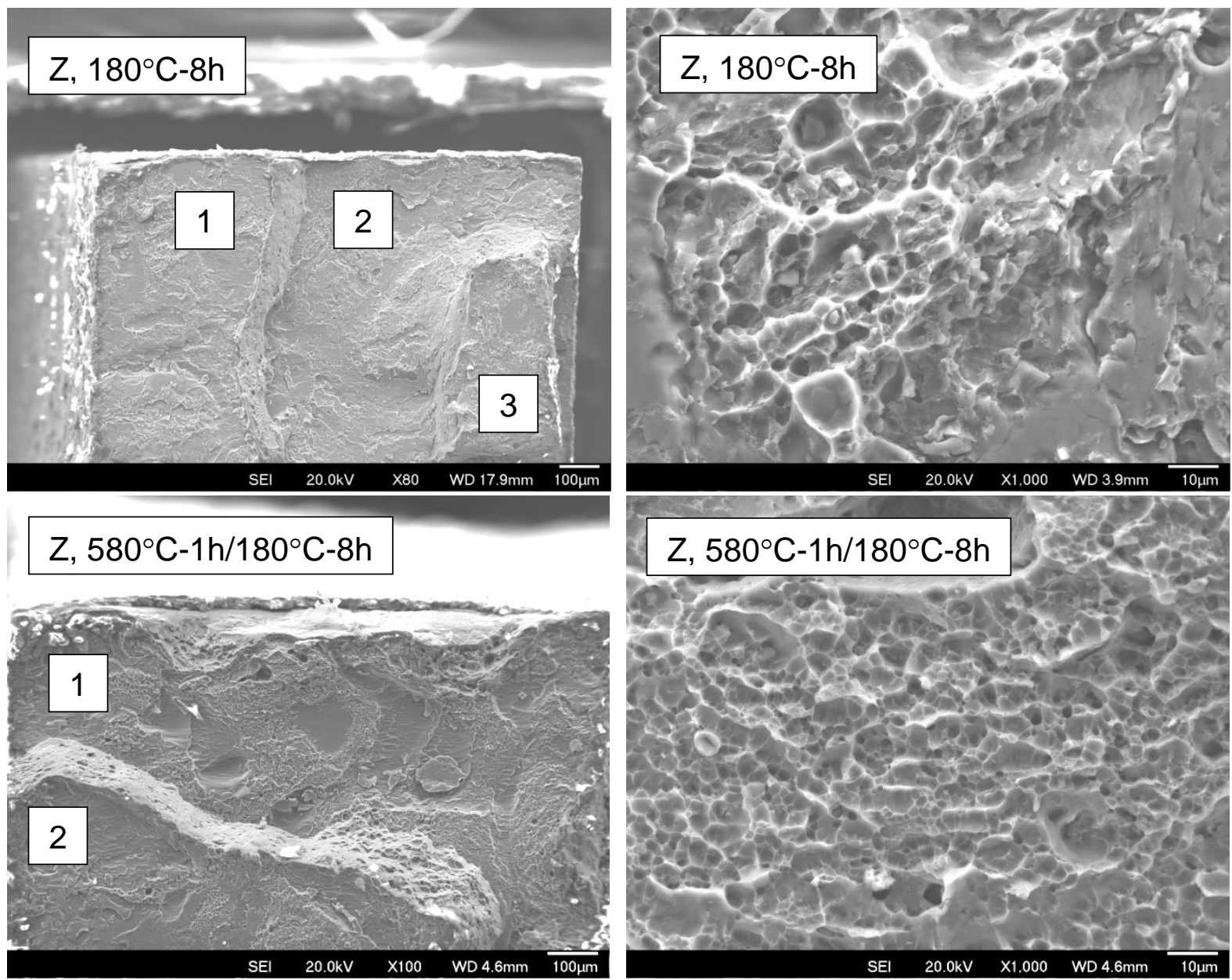

Figure 7. The fracture surface of Z-specimens after annealing. The number (1-2-3 or 1-2) indicate the layers involved in the fracture. 
When tested after an aging treatment at $180^{\circ} \mathrm{C}$, the increase in the dimpled fraction was observed as shown in Figure 7. The most important feature was that the failure did not occur along a single layer. The fractography analysis revealed crack transition between the layers (see features marked 1-3 in Figure 7). The dominating features of the fracture surface were ductile dimples with small locations of cleavage brittle failure. The brittle cleavage regions are possibly where the cracks initially appeared.

Based on this observation, it can be hypothesized that the cracks initially nucleated at the interface possibly adjacent to the void (hence underwent cleavage) and propagated along the interface region. Crack propagation continues until the crack gets arrested at a local strong point. Local strong points at the interface lead to the crack being deflected and propagating through the bulk material to a different layer. This is also evident from all the optical micrographs of the fractured samples shown in Figure 8.
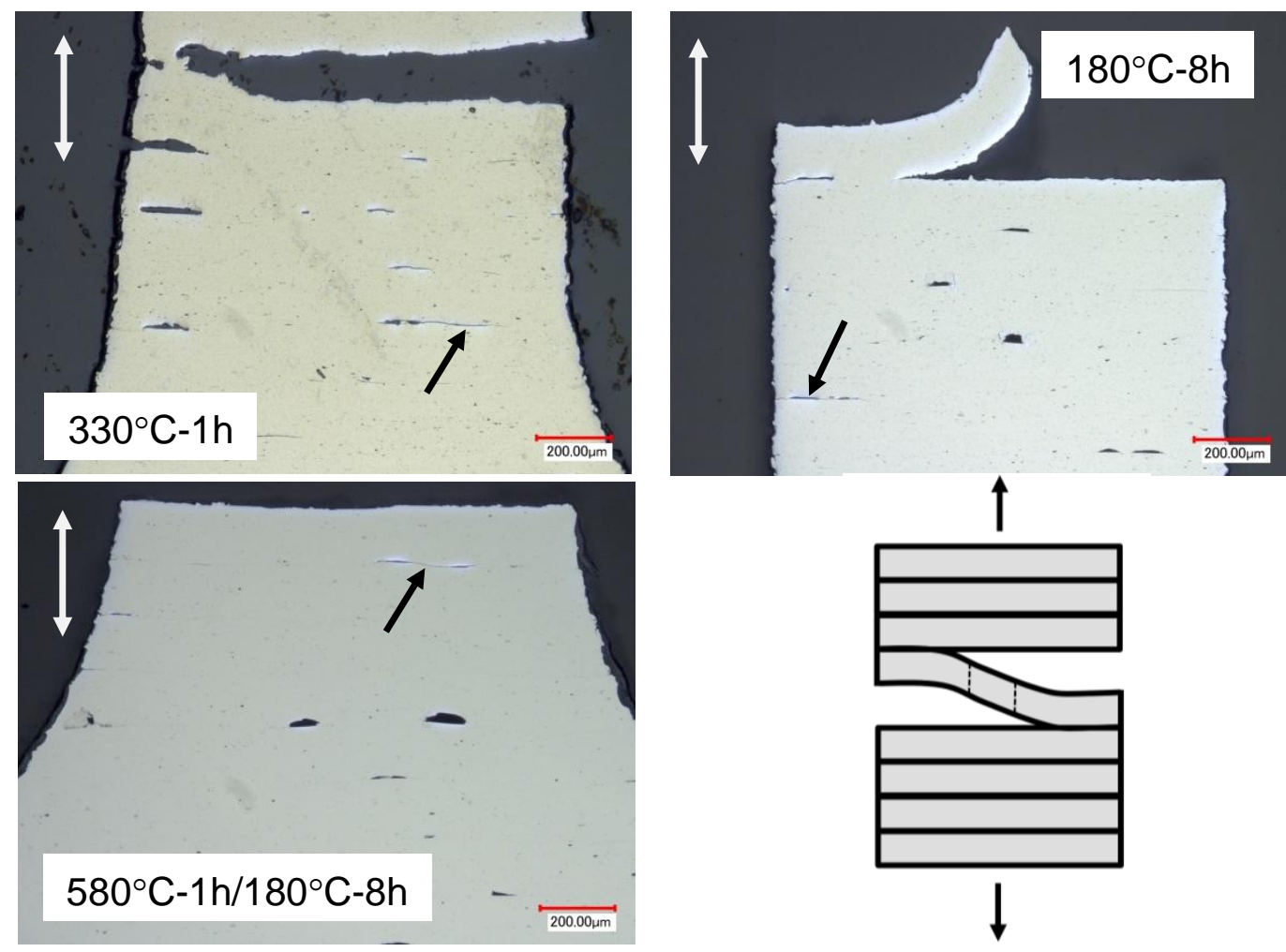

Figure 8. Cross-section of the Z-specimens after tensile testing and the scheme showing the delayering during the fracture. White arrows show tensile direction. Small cracks, developed along the interfaces during the test, are pointed by black arrows.

The analysis of the cross-sections of the fractured Z-specimens (Figure 8) showed multiple internal cracks propagated along the interfaces. It appears that the cracks in most cases originated 
from voids thus confirming the above-discussed hypothesis that the voids after PWHT became a major fracture-controlling factor.

For the X-and Y-specimens, the fracture surface always revealed a layered structure, Figure 9. Each layer corresponded to a separate single foil. The foils in the neck showed pronounced delayering along the interfaces, and each foil formed a separate, narrow "neck." Ductile dimples dominated the fracture surface regardless the thermo-treatment. Interestingly, the weldinginduced voids were not visible and disappeared outside the fracture area in the X-and Yspecimens. Most likely, plastic strain led to the void closure.

Void evolution and fracture process kinetics are very important since the properties of the layered UAM-produced materials (e.g., elastic constants [36], fatigue behavior [37]) are sensitive to the void presence and morphology. However, investigating this process in detail will require a separate, on-purpose work based on the in-situ experiment techniques. Most likely, an X-ray tomography (XRT) will be the most appropriate tool [38,39]. Another attractive method may be an in-situ EBSD analysis allowing for local grain rotation and texture analysis [40] or DIC coupled with SEM for precise strain measurements and analysis at the micro level [41]. Both methods, XRT and in-situ SEM-EBSD, will be considered in the future work.

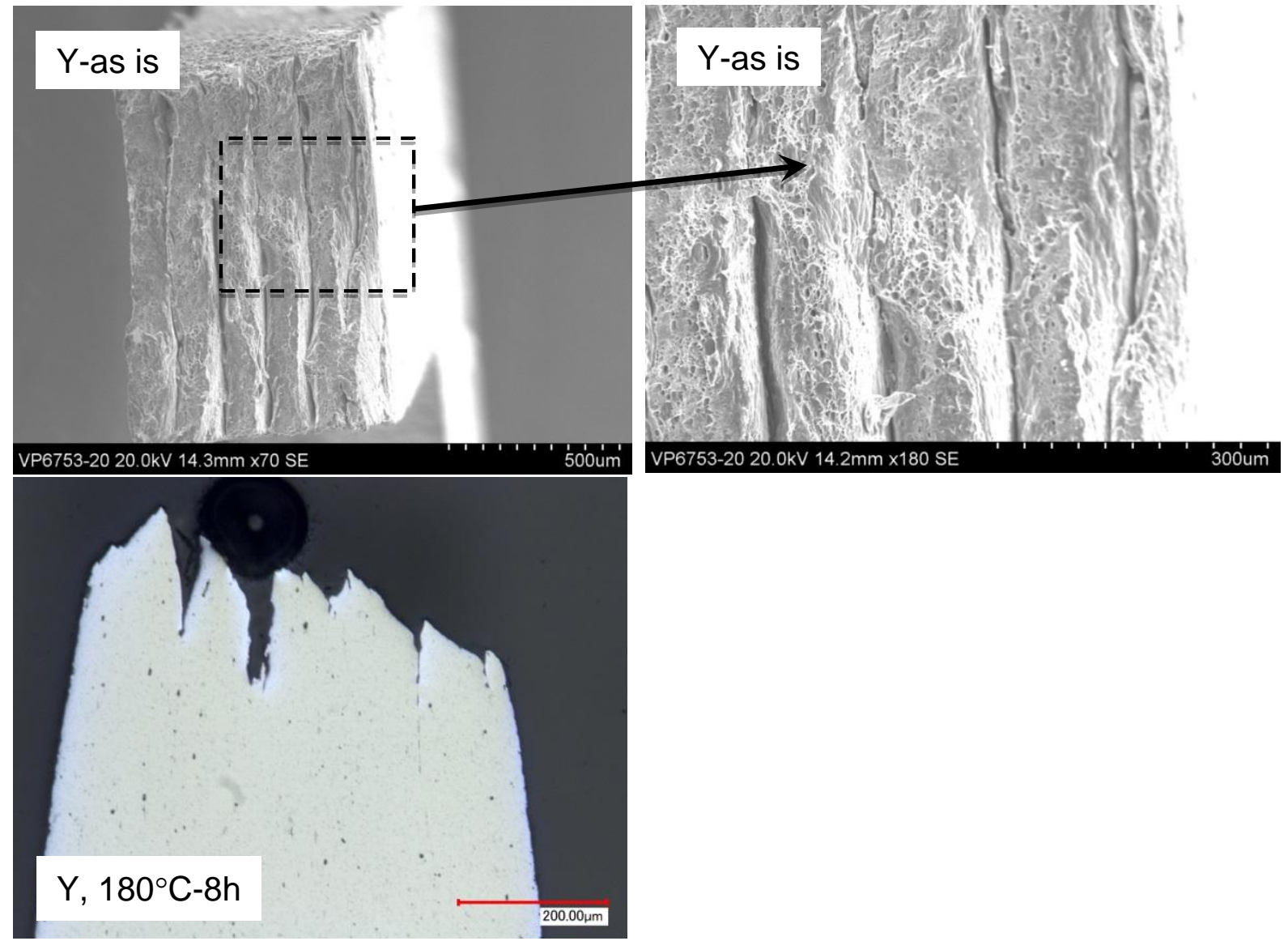

Figure 9. Representative SEM images of the fracture surface (top) and specimen cross-section 


\section{Microstructure characterization of the interfaces}

The Z-strength level enhancement analyzed above could be driven by the formation of the $\mathrm{Mg}_{2} \mathrm{Si}$ precipitates during the PWHT, annealing out of the previously formed shear bands, grain growth across the interfaces, or a combination of these processes. Hence, to understand the effect of PWHT on the microstructure, EBSD analysis was performed on the interfaces and bulk material.
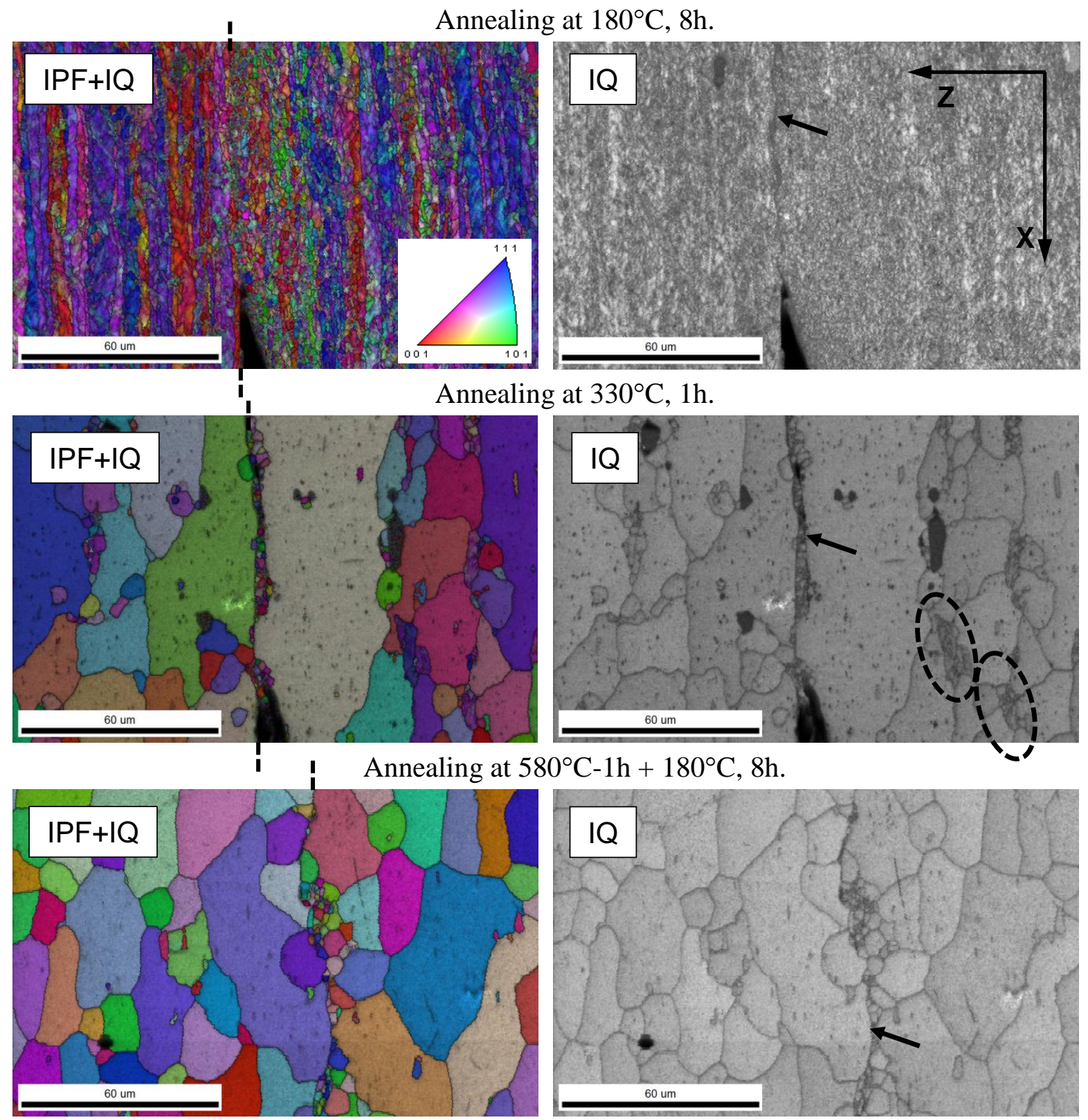

Figure 10. Representative Inverse Pole Figure (IPF, colored in the X-direction) and Image Quality (IQ) maps obtained at moderate resolution ( $0.5 \mu \mathrm{m}$ step size) for specimens annealed at different temperatures. Black arrows and dashed lines show the welding interface location. Color IPF key is the same for all IPFs throughout the article. X, Z - orientation of the specimen during UAM-process, Figure 1. 
The EBSD data presented in Figure 10 and Figure 11 shows the microstructure after various heat treatments. As expected, there was no significant grain growth after aging treatment $\left(180^{\circ} \mathrm{C}-8 \mathrm{~h}\right)$. The grain size remained close to the as-received conditions discussed in [11]. One can see elongated and fragmented grains in the parent tape and significantly refined $(\sim 1-2 \mu \mathrm{m})$ grains at the interface, Figure 10. Extensive texture analysis and electron microscopy [42-45] showed that the interface structure developed by a dynamic recrystallization process driven by the intense shear deformation. A comprehensive analysis of the texture components after the heat treatment is beyond the scope of the present study.

Annealing at $180^{\circ} \mathrm{C}, 8 \mathrm{~h}$.

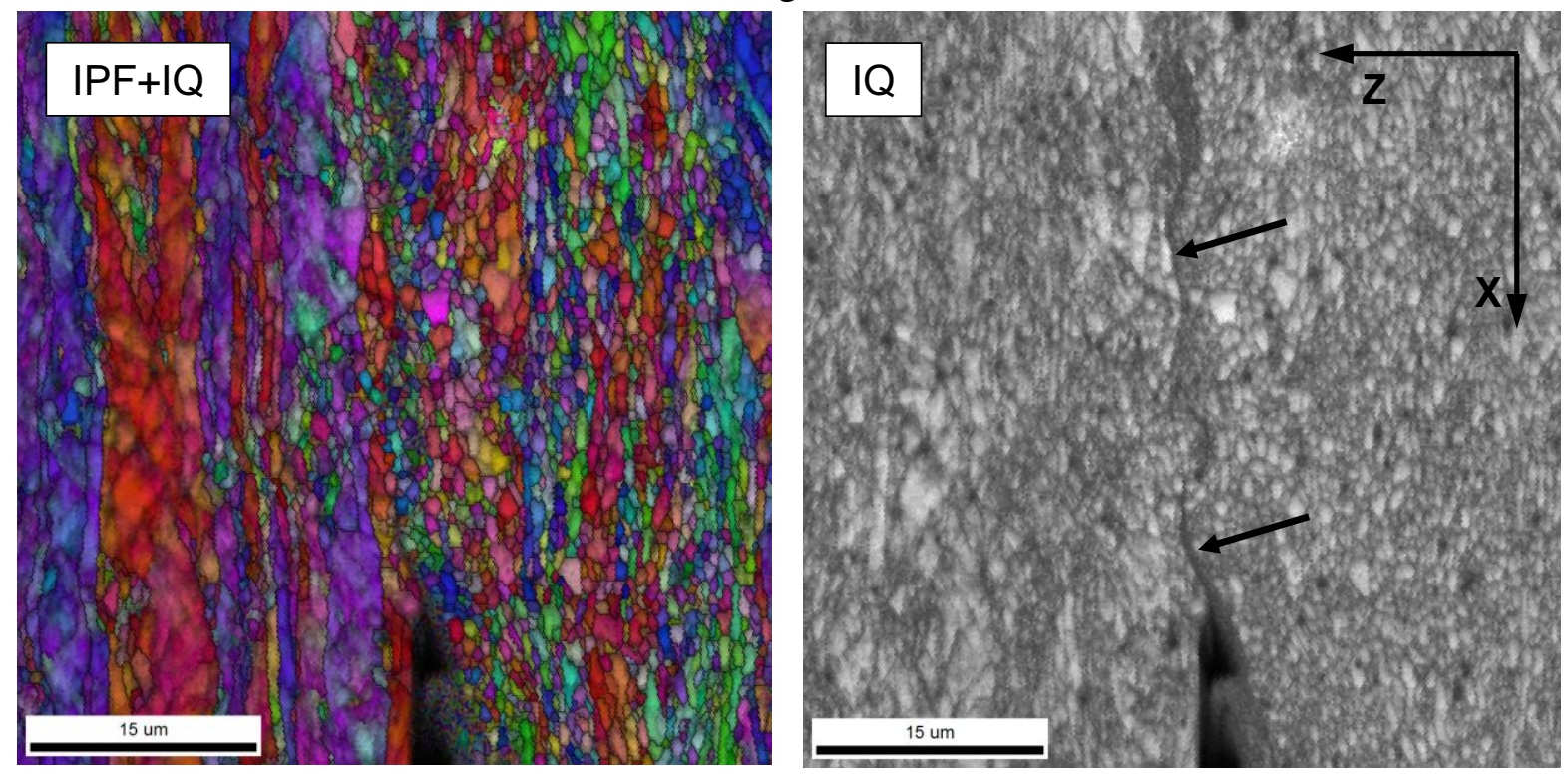

Annealing at $330^{\circ} \mathrm{C}, 1 \mathrm{~h}$.
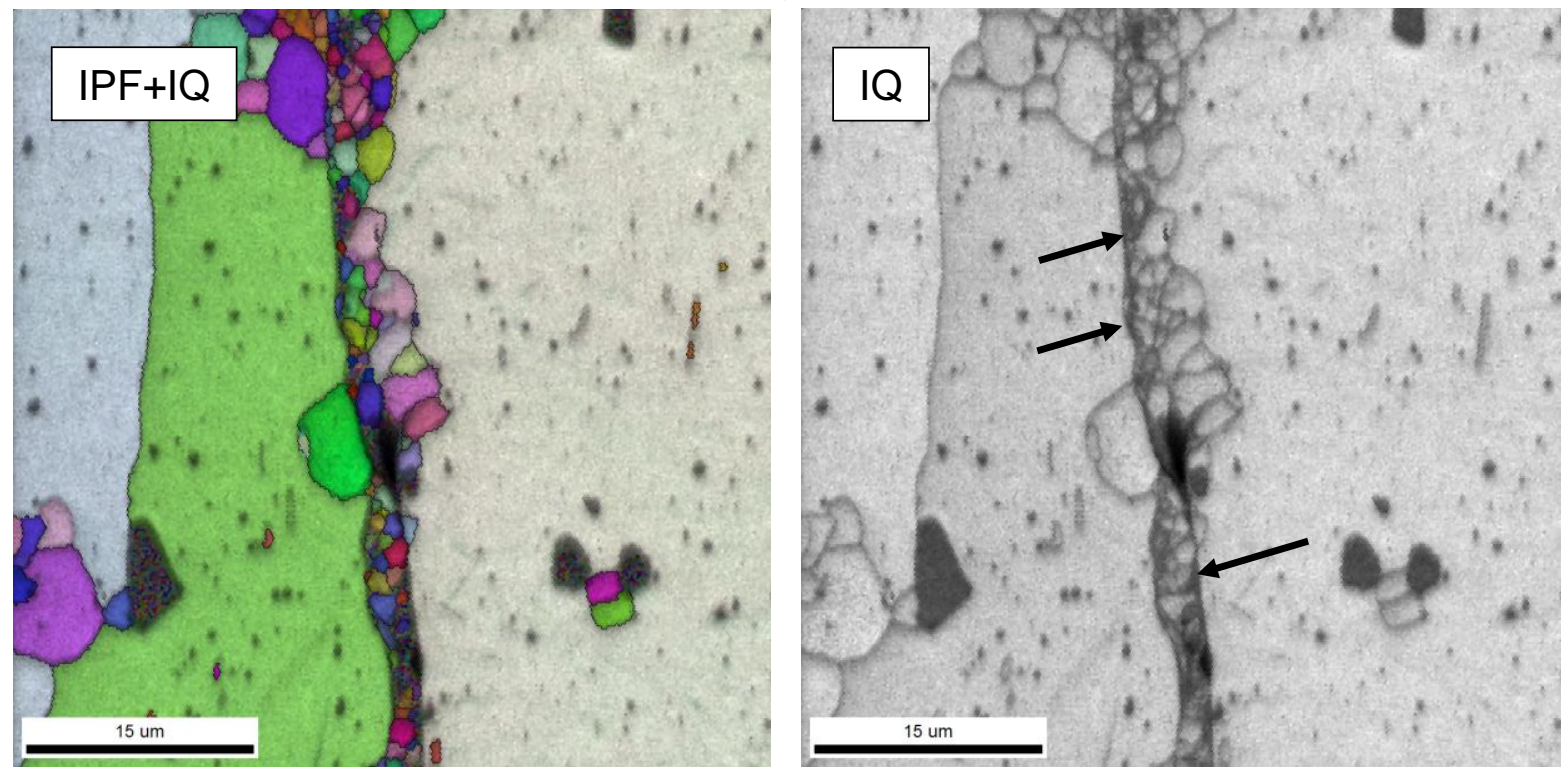

Figure 11. High-resolution (step size of $200 \mathrm{~nm}$ ) IPF and IQ maps for the annealed specimens showing the grain structure evolution near the welding interface (shown by black arrows). 
According to the EBSD results, the increase in the strength on loading along the Z-axis could not be attributed to the grain growth across the interface and interface disappearance. The exact mechanism of the fracture stress improvement after aging at $180^{\circ} \mathrm{C}$ is not clear. Most likely, it could be attributed to the restoring of the precipitation structure. Also, previous work [11] performed using digital image correlation in conjunction with electron microscopy, attributed the reduction in properties of the as-received material to the presence shear-bands and localized deformation areas. The heat treatment at $180^{\circ} \mathrm{C}$ could have annealed these areas or, at least, reduce the strain localization degree. This prevented in the cracks nucleating spontaneously from pre-existing shear bands at the interface.

The absence of the grain growth at $180^{\circ} \mathrm{C}$ was attributed to the low temperature $\left(<0.5 \mathrm{~T}_{\mathrm{m}}\right.$, melting point) and it was speculated that heat treatment at $330^{\circ} \mathrm{C}$ should result in significant grain growth since the temperature is close to $0.5 \mathrm{~T}_{\mathrm{m}}$. Indeed, strong grain growth was observed (Figure 10, Figure 11); grain shape became slightly elliptical, elongated in X-direction. Interestingly, the largest grains were often observed near the welding interface.

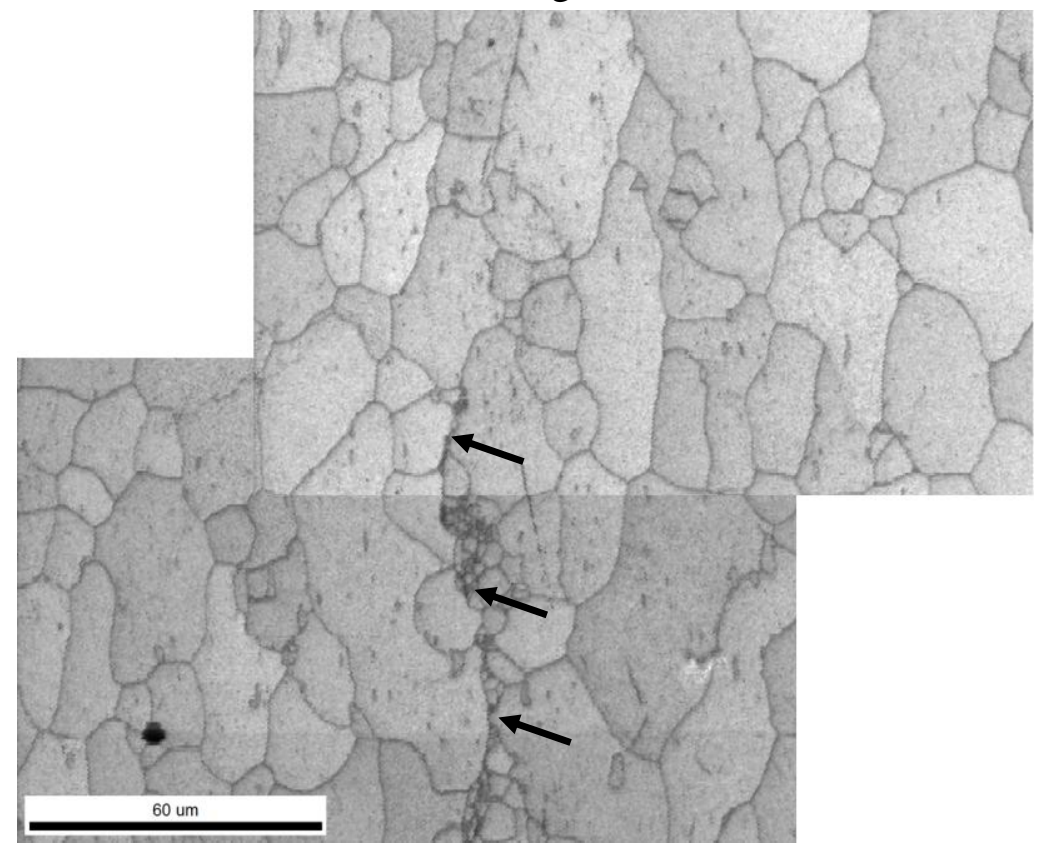

Figure 12. Overlapping IQ maps showing the welding interface (black arrows) disappearance and grain migration across the interface (annealing at $580^{\circ} \mathrm{C}-1 \mathrm{~h}$ with the following aging). The interface is well visible in the bottom image (black arrows) but disappears in the top one.

Surprisingly, grain structure at the interface itself remained unchanged. Grains directly adjacent to the interface lines experienced very limited, if any, growth. Typically, small grains formed specific chains along the former welding interfaces, Figure 11, and there was no migration of the grains across the interfaces. Sometimes, groups of small non-recrystallized grains were observed in the bulk, far from interfaces (Figure 10, dashed ovals in the IQ map). This result is unintuitive 
and was unexpected. One may argue that the limited grain growth at the interface is caused by a partial recrystallization already occurred during welding (high local temperatures due to near adiabatic heating). Another reason may be a grain boundary pinning by precipitates, oxide particles, or non-equilibrium solutes. A set of detailed microstructural studies at lower length scales are currently ongoing to elucidate the source of this remarkable grain size stability at the interface and will be reported in a future publication.

Annealing at $580^{\circ} \mathrm{C}-1 \mathrm{~h}$ also led to the recrystallization and grain growth; average grain size was slightly smaller compared to the $330^{\circ} \mathrm{C}$ - $1 \mathrm{~h}$ case. Groups of small grains near the interface still existed, even after annealing at $>0.9 \mathrm{~T}_{\mathrm{m}}$, but they covered only a limited part of the interface area, roughly, half. Interface lines became less visible and in many cases disappeared, and grain migrated across the interface, as illustrated in Figure 12. The partial disappearance of the welding interfaces agrees well with the fractography results on the crack propagation, Figure 7. The interface disappearance and aging resulted in an increase in the Z-axis fracture stress by a factor of more than 3 . This could be rationalized by both precipitation strengthening and interface disappearance.

\section{Conclusions}

Influence of the post-weld heat treatments (PWHT) on the mechanical properties of the aluminum alloy 6061 fabricated using UAM was investigated using mechanical testing coupled with DIC analysis, SEM, and EBSD. It was established that PWHT resulted in significant improvement in mechanical properties. In particular, the fracture stress of the specimens, when loaded along the Z-direction, increased by more than a factor of 3 .

PWHT also significantly influenced the tensile behavior of the UAM-produced material. The Xand $Y$-direction specimens after annealing demonstrated specific deformation behavior with propagating deformation bands. In the $\mathrm{Y}$-specimens, these bands had unexpectedly high strain amplitude. This phenomenon was different from a commonly observed Portevin-Le-Chatelier effect, but its nature is not fully clear.

EBSD showed that the interfaces were not affected by heat treatments at $180^{\circ} \mathrm{C}$. Annealing at $330^{\circ} \mathrm{C}$ led to the recrystallization in the bulk material, but interfaces survived; chains of small grains remained along the interface lines. A high-temperature heat treatment $\left(580^{\circ} \mathrm{C}\right)$ caused an observable grain growth and only partial disappearance of the small grains at the interface.

\section{Acknowledgements}

This work was sponsored by Laboratory Directed R\&D funds at Oak Ridge National Laboratory. EBSD analysis was performed at Center for Nano phase Materials (CNMS), Oak Ridge National Laboratory, sponsored by the Department of Energy, Office of Basic Energy Sciences. The 
authors also gratefully acknowledge the U.S. Department of Energy, Office of Energy Efficiency and Renewable Energy, Advanced Manufacturing Office. The authors also would like to thank Dr. A. Hehr for fruitful comments and discussion.

\section{References}

[1] M. Norfolk and H. Johnson, "Solid-state additive manufacturing for heat exchangers," JOM, vol. 67, 2015, pp. 655-659.

[2] P.J. Wolcott, A. Hehr, and M.J. Dapino, "Optimized welding parameters for Al 6061 ultrasonic additive manufactured structures," Journal of Materials Research, vol. 29, 2014, pp. 2055-2065.

[3] D. Li and R.C. Soar, "Plastic flow and work hardening of Al alloy matrices during ultrasonic consolidation fibre embedding process," Materials Science and Engineering: A, vol. 498, 2008, pp. 421-429.

[4] J. Li, T. Monaghan, S. Masurtschak, A. Bournias-Varotsis, R.J. Friel, and R.A. Harris, "Exploring the mechanical strength of additively manufactured metal structures with embedded electrical materials," Materials Science and Engineering: A, vol. 639, 2015, pp. 474-481.

[5] G.S. Kelly, M.S. Just, S.G. Advani, and J.W. Gillespie, "Energy and bond strength development during ultrasonic consolidation," Journal of Materials Processing Technology, vol. 214, 2014, pp. 1665-1672.

[6] M. Sriraman, M. Gonser, H.T. Fujii, S. Babu, and M. Bloss, "Thermal transients during processing of materials by very high power ultrasonic additive manufacturing," Journal of Materials Processing Technology, vol. 211, 2011, pp. 1650-1657.

[7] J. Obielodan and B. Stucker, "A fabrication methodology for dual-material engineering structures using ultrasonic additive manufacturing," The International Journal of Advanced Manufacturing Technology, vol. 70, 2014, pp. 277-284.

[8] P.J. Wolcott, "Ultrasonic Additive Manufacturing: Weld Optimization for Aluminum 6061, Development of Scarf Joints for Aluminum Sheet Metal, and Joining of High Strength Metals," The Ohio State University, 2015.

[9] D. Schick, R. Hahnlen, R. Dehoff, P. Collins, S. Babu, M. Dapino, and J. Lippold, "Microstructural Characterization of Bonding Interfaces in Aluminum 3003 Blocks Fabricated by Ultrasonic Additive Manufacturing-Methods were examined to link microstructure and linear weld density to the mechanical properties of ultrasonic additive manufacturing," Welding Journal, vol. 89, 2010, p. 105S.

[10] C. Kong, R. Soar, and P. Dickens, "Characterisation of aluminium alloy 6061 for the ultrasonic consolidation process," Materials Science and Engineering: A, vol. 363, 2003, pp. 99-106.

[11] N. Sridharan, M. Gussev, R. Seibert, C. Parish, M. Norfolk, K. Terrani, and S.S. Babu, "Rationalization of anisotropic mechanical properties of Al-6061 fabricated using ultrasonic additive manufacturing," Acta Materialia, vol. 117, 2016, pp. 228-237.

[12] G.J. Ram, Y. Yang, and B. Stucker, "Effect of process parameters on bond formation during ultrasonic consolidation of aluminum alloy 3003," Journal of Manufacturing Systems, vol. 25, 2006, pp. 221-238. 
[13] A.G. Truog, "Bond improvement of $\mathrm{Al} / \mathrm{Cu}$ joints created by very high power ultrasonic additive manufacturing," The Ohio State University, 2012.

[14] C. Hopkins, M. Dapino, and S. Fernandez, "Statistical characterization of ultrasonic additive manufacturing Ti/Al composites," Journal of Engineering Materials and Technology, vol. 132, 2010, p. 041006.

[15] C. Kong, R. Soar, and P. Dickens, "Optimum process parameters for ultrasonic consolidation of 3003 aluminium," Journal of materials processing technology, vol. 146, 2004, pp. 181-187.

[16] P. Wolcott, A. Hehr, C. Pawlowski, and M. Dapino, "Process improvements and characterization of ultrasonic additive manufactured structures," Journal of Materials Processing Technology, vol. 233, 2016, pp. 44-52.

[17] R. Ahmad and M. Bakar, "Effect of a post-weld heat treatment on the mechanical and microstructure properties of AA6061 joints welded by the gas metal arc welding cold metal transfer method," Materials \& Design, vol. 32, 2011, pp. 5120-5126.

[18] M.W. Dewan, J. Liang, M. Wahab, and A.M. Okeil, "Effect of post-weld heat treatment and electrolytic plasma processing on tungsten inert gas welded AISI 4140 alloy steel," Materials \& Design, vol. 54, 2014, pp. 6-13.

[19] M. Temmar, M. Hadji, and T. Sahraoui, "Effect of post-weld aging treatment on mechanical properties of Tungsten Inert Gas welded low thickness 7075 aluminium alloy joints," Materials \& Design, vol. 32, 2011, pp. 3532-3536.

[20] D.E. Schick, "Characterization of aluminum 3003 ultrasonic additive manufacturing," The Ohio State University, 2009.

[21] K. Sojiphan, "Effects of Very High Power Ultrasonic Additive Manufacturing Process Parameters on Hardness, Microstructure, and Texture of Aluminum 3003-H18 Alloy," The Ohio State University, 2015.

[22] H. Kim, S. Cho, and C. Kang, "Evaluation of microstructure and mechanical properties by using nano/micro-indentation and nanoscratch during aging treatment of rheo-forged $\mathrm{Al}$ 6061 alloy," Materials Science and Engineering: A, vol. 485, 2008, pp. 272-281.

[23] H.J. Rack and R.W. Krenzer, "Thermomechanical treatment of high purity 6061 aluminum," Metallurgical Transactions A, vol. 8, 1977, pp. 335-346.

[24] M. Sutton, J. Orteu, and H. Schreier, "Digital image correlation (DIC)," Image Correlation for Shape, Motion and Deformation Measurements: Basic Concepts, Theory and Applications, 2009.

[25] T. Zhang, J. Jiang, B.A. Shollock, T.B. Britton, and F.P. Dunne, "Slip localization and fatigue crack nucleation near a non-metallic inclusion in polycrystalline nickel-based superalloy," Materials Science and Engineering: A, vol. 641, 2015, pp. 328-339.

[26] H. Jiang, Q. Zhang, X. Chen, Z. Chen, Z. Jiang, X. Wu, and J. Fan, "Three types of Portevin-Le Chatelier effects: experiment and modelling," Acta materialia, vol. 55, 2007, pp. 2219-2228.

[27] P. Cetlin, A. Güleç, and R. Reed-Hill, "Serrated flow in aluminum 6061 alloy," Metallurgical Transactions, vol. 4, 1973, pp. 513-517.

[28] M.R. Rezaei, M.R. Toroghinejad, and F. Ashrafizadeh, "Effects of $\{A R B\}$ and ageing processes on mechanical properties and microstructure of 6061 aluminum alloy," Journal of Materials Processing Technology, vol. 211, 2011, pp. 1184-1190. 
[29] Y. Xu, W. Zhong, Y. Chen, L. Shen, Q. Liu, Y. Bai, and M. Meyers, "Shear localization and recrystallization in dynamic deformation of 8090 Al-Li alloy," Materials Science and Engineering: A, vol. 299, 2001, pp. 287-295.

[30] Y.I. Golovin, V.I. Ivolgin, M.A. Lebedkin, and D.A. Sergunin, "Regions of the portevin-Le chatelier effect existing under the conditions of continuous room-temperature indentation of an Al-2.7\% Mg alloy," Physics of the Solid State, vol. 46, 2004, pp. 1671-1673.

[31] T.A. Lebedkina, M.A. Lebyodkin, J.-P. Chateau, A. Jacques, and S. Allain, "On the mechanism of unstable plastic flow in an austenitic FeMnC \{TWIP $\}$ steel," Materials Science and Engineering: A, vol. 519, 2009, pp. 147-154.

[32] P. McCormick and C. Ling, "Numerical modelling of the Portevin-Le Chatelier effect," Acta metallurgica et materialia, vol. 43, 1995, pp. 1969-1977.

[33] D.A. Zhemchuzhnikova, M.A. Lebyodkin, T.A. Lebedkina, and R.O. Kaibyshev, "Unusual behavior of the Portevin-Le Chatelier effect in an AlMg alloy containing precipitates," Materials Science and Engineering: A, vol. 639, 2015, pp. 37-41.

[34] M. Mazière and S. Forest, "Strain gradient plasticity modeling and finite element simulation of Lüders band formation and propagation," Continuum Mechanics and Thermodynamics, vol. 27, 2015, pp. 83-104.

[35] Y.Z. Shen, K.H. Oh, and D.N. Lee, "The effect of texture on the Portevin-Le Chatelier effect in 2090 Al-Li alloy," Scripta Materialia, vol. 51, 2004, pp. 285-289.

[36] D. Foster, M. Dapino, and S. Babu, "Elastic constants of ultrasonic additive manufactured Al 3003-H18," Ultrasonics, vol. 53, 2013, pp. 211-218.

[37] X.-H. He, H.-J. Shi, Y.-D. Zhang, W.-X. Fu, Z.-G. Yang, and C.E. Wilkinson, "In-situ scanning electron microscopy studies of small fatigue crack growth in ultrasonic consolidation bonded aluminum 2024 laminated structure," Materials Letters, vol. 112, 2013, pp. 47-50.

[38] J.-Y. Buffiere, E. Maire, J. Adrien, J.-P. Masse, and E. Boller, "In situ experiments with X ray tomography: an attractive tool for experimental mechanics," Experimental mechanics, vol. 50, 2010, pp. 289-305.

[39] C. Gupta, E. Van de Casteele, and J. Chakravartty, "Imaging of voids due to deformation in alloy steel using micro-focus X-ray beam," Nuclear Instruments and Methods in Physics Research Section B: Beam Interactions with Materials and Atoms, vol. 267, 2009, pp. 3488-3490.

[40] P. Chen, S. Mao, Y. Liu, F. Wang, Y. Zhang, Z. Zhang, and X. Han, "In-situ EBSD study of the active slip systems and lattice rotation behavior of surface grains in aluminum alloy during tensile deformation," Materials Science and Engineering: A, vol. 580, 2013, pp. 114-124.

[41] Y. Zhang, T.D. Topping, E.J. Lavernia, and S.R. Nutt, "Dynamic micro-strain analysis of ultrafine-grained aluminum magnesium alloy using digital image correlation," Metallurgical and Materials Transactions A, vol. 45, 2014, pp. 47-54.

[42] R. Dehoff and S. Babu, "Characterization of interfacial microstructures in 3003 aluminum alloy blocks fabricated by ultrasonic additive manufacturing," Acta Materialia, vol. 58, 2010, pp. 4305-4315.

[43] H.T. Fujii, M. Sriraman, and S. Babu, "Quantitative evaluation of bulk and interface microstructures in Al-3003 alloy builds made by very high power ultrasonic additive manufacturing," Metallurgical and Materials Transactions A, vol. 42, 2011, pp. 40454055. 
[44] H. Ji, J. Wang, and M. Li, "Evolution of the bulk microstructure in 1100 aluminum builds fabricated by ultrasonic metal welding," Journal of Materials Processing Technology, vol. 214, 2014, pp. 175-182.

[45] S. Shimizu, H.T. Fujii, Y.S. Sato, H. Kokawa, M.R. Sriraman, and S.S. Babu, "Mechanism of weld formation during very-high-power ultrasonic additive manufacturing of Al alloy 6061," Acta Materialia, vol. 74, 2014, pp. 234-243. 